of Australia, the farthest away, transmission must travel through twilight conditions whichever path round the world is used. It was not expected therefore that wave-lengths of 15 metres, using the daylight path, or 37 metres using the dark path, would give trustworthy service. Both can be used for short periods but their useful duration is limited and uncertain. The twilight band (25-29 metres) has been found to be the best. In the Indian zone it has been found that 17 metre transmissions are very satisfactory. In the case of Africa, as it lies almost due south, shorter wave-lengths are used during the day, intermediate wave-lengths at dusk and at nighttime 32 metre wave-lengths or even longer can be used. It is found better to divide Africa into two zones. The great circle path to Canada passes very near to the north pole and even in summer it is not a true daylight path. A satisfactory day wave for Canada is of the order of 19 metres, but night waves of 31 and 50 and sometimes as high as 70 or 80 metres have been used. The B.B.C. deserves great credit for having overeome so successfully many of the difficulties connected with the most ambitious project ever attempted in broadcasting.

\section{Standardisation of Electricity Supply}

IN a paper read on May 31 to a meeting of the Incorporated Municipal Electrical Assuciation (the I.M.E.A.), which was held in Liverpool, L. Romero discussed the standardisation of methods for distributing electricity and for its sale. He recently addressed a questionnaire to sixty of the largest municipal supply undertakings in Great Britain, and nearly all had replied explaining the systems they used and in particular the voltages which they adopted to supply their consumers. It was decided officially some years ago that the standard system of supply should be the alternating current system and that the standard pressure for domestic supply should be 230 volts. The replies received show that about a third of the municipal undertakings are maintaining voltages which are not standard and that the number of consumers using these voltages is rapidly increasing. The reason given for not adopting the standard is that the change would be expensive. This is a short-sighted policy, as it causes expense to consumers and is a definite obstacle in the way of cheapening electrical lamps and appliances. Several countries abroad also suffer from this lack of standardisation. Luckily, in Great Britain, the progress made in changing from D.C. to A.C. supply is much more satisfactory. Many people think that the supply of electricity should be managed on a national basis, their principal argument being the lack of standardisation that otherwise ensues. Presumably local authorities desire to manage their own electricity supply. Some of them would therefore do well to regard standardisation from a broader point of view.

\section{Electrification of Collieries}

ALtнобан great progress has been made during recent years in the electrification of collieries, about one third of the total power utilised is still generated mechanically. According to the Electrical Review of June 29, the total horse-power of the motors in use in collieries is now about $1,900,000$. This is equivalent to more than ten per cent of the capacity of all the plant connected to the public supply mains in Great Britain. Of the electricity used, only about thirty per cent is supplied by statutory authorities. Doubtless this percentage will rapidly increase, as power can be produced more cheaply at points away from the pithead where a more abundant water supply is available for condensing purposes. It is satisfactory to notice that, despite the increase in the use of electricity, the number of electrical accidents is steadily decreasing. This is due to the design of flame-proof structures and flame-proof apparatus. Owing to the high standards adopted by the Association of Mining Engineers, the costs of maintenance have also rapidly diminished. The fixing of minimum standards for illumination for portable lamps is a notable advance. We think that inventors ought to turn their attention to the development of a fixed lighting system which would be safe to use at all parts of the coal face.

\section{Interference with Radio Supply by Electric Lighting}

IT is well known that when direct current supply is used for electric lighting, the contacts of the switches and fuses often get badly corroded after a few years' operation. This usually causes little, if any, inconvenience in the lighting of the house or in the use of electric appliances, but if a radio receiver be installed the loud speaker produces most unpleasant noises. This is often attributed quite wrongly to some fault in the set. In many cases the noises are got rid of by having the electric wiring overhauled. According to a paper in the Electrical Review of June 1 by V. Z. de Ferranti, many domestic electrical appliances also cause bad radio reception. As examples he gives electric bells operated from the mains, children's electric toy trains, a bad contact in an electric fire and, worst of all, any piece of equip ment driven by a motor. He points out that it is far easier to supply equipment which can be trusted to cause no interference than to eliminate by special devices the interference caused by equipment already installed. The special devices are often expensive. He estimates that there are now two and a half million mains-operated radio sets in Great Britain. Collectively, they take about 150,000 kilowatts and the average demand is about two hours a day. In addition, the demand for this load is outside the busy hour of supply and it is therefore desirable to the electricity companies. There is quite an appreciable number of small house-holders who have availed themselves of electric supply primarily in order to be able to use it for radio receiving sets.

\section{Secret Radio-telephony}

A ScIence Service Mail Report dated May 28 states that Dr. S. Chiba, of the Tokyo Electric Co., has developed a secret method of radio-telephonic communication. According to the description, the 